\title{
THE
}

\section{Source Apportionment of Gaseous and Particulate PAHs from Traffic Emission Using Tunnel Measurements in Shanghai, China}

Ying Liu

Siyao Wang

Rainer Lohmann

University of Rhode Island, rlohmann@uri.edu

$\mathrm{Na} \mathrm{Yu}$

Chenkai Zhang

Follow this and additional works at: https://digitalcommons.uri.edu/gsofacpubs

The University of Rhode Island Faculty have made this article openly available.

Please let us know how Open Access to this research benefits you.

This is a pre-publication author manuscript of the final, published article.

Terms of Use

This article is made available under the terms and conditions applicable towards Open Access

Policy Articles, as set forth in our Terms of Use.

\section{Citation/Publisher Attribution}

Ying Liu, Siyao Wang, Rainer Lohmann, Na Yu, Chenkai Zhang, Yi Gao, Jianfu Zhao, Limin Ma. (2015).

"Source apportionment of gaseous and particulate PAHs from traffic emission using tunnel measurements in Shanghai, China." Atmospheric Environment. 107: 129-136.

Available at: http://dx.doi.org/10.1016/j.atmosenv.2015.02.041

This Article is brought to you for free and open access by the Graduate School of Oceanography at DigitalCommons@URI. It has been accepted for inclusion in Graduate School of Oceanography Faculty Publications by an authorized administrator of DigitalCommons@URI. For more information, please contact digitalcommons-group@uri.edu. 
Authors

Ying Liu, Siyao Wang, Rainer Lohmann, Na Yu, Chenkai Zhang, Yi Gao, Jianfu Zhao, and Limin Ma

This article is available at DigitalCommons@URI: https://digitalcommons.uri.edu/gsofacpubs/64 


\section{Source apportionment of gaseous and particulate PAHs from traffic}

\section{emission using tunnel measurements in Shanghai, China}

YING LIU a, b, *, SIYAO WANG a, RAINER LOHMANN ${ }^{b}$, NA YU a, CHENKAI ZHANG a, YI $\mathrm{GAO}^{\text {a }}$, JIANFU ZHAO a, LIMIN MA ${ }^{\mathrm{a}, *}$

a State Key Laboratory of Pollution Control and Resources Reuse, Key Laboratory of Shanghai Climate Change Response for Urban Areas, College of Environmental Science and Engineering, Tongji University, Shanghai 200092, China.

b Graduate School of Oceanography, University of Rhode Island, Narragansett, RI 02882, USA

\section{ABSTRACT}

Understanding sources and contributions of gaseous and particulate PAHs from traffic-related pollution can provide valuable information for alleviating air contamination from traffic in urban areas. On-road sampling campaigns were comprehensively conducted during 2011-2012 in an urban tunnel of Shanghai, China. 2-3 rings PAHs were abundant in the tunnel's gas and particle phases. Diagnostic ratios of PAHs were statistically described; several were significantly different between the gas and particle phases. Principal component analysis (PCA), positive matrix factorization (PMF), bivariate correlation analysis and multiple linear regression analysis (MLRA) were applied to apportion sources of gaseous and particulate PAHs in the tunnel. Main sources of the gaseous PAHs included evaporative emission of fuel, high-temperature and low-temperature combustion of fuel, accounting for $50-51 \%, 30-36 \%$ and $13-20 \%$, respectively. Unburned fuel particles (56.4-78.3\%), high-temperature combustion of fuel (9.5-26.1\%) and gas-to-particle condensation (12.2-17.5\%) were major contributors to the particulate PAHs. The

\footnotetext{
* Corresponding author

Ying Liu, Phone/Fax: 86-21-65984268; E-mail: liu_ying@tongji.edu.cn, liuying.tongji@gmail.com; Address: 1239 Siping Rd. Shanghai 200092, China

* Corresponding author

Limin Ma, Phone/Fax: 86-21-65980439; E-mail: 1mma@tongji.edu.cn.
} 
result reflected, to a large extent, PAH emissions from the urban traffic of Shanghai. Improving fuel efficiency of local vehicles will greatly reduce contribution of traffic emission to atmospheric PAHs in urban areas. Source apportionment of $\mathrm{PM}_{10}$ mass was also performed based on the organic component data. The results showed that high-temperature combustion of fuel and gas-to-particle condensation contributed to $15-18 \%$ and $7-8 \%$ of $\mathrm{PM}_{10}$ mass, respectively, but $55-57 \%$ of the particle mass was left unexplained. Although the results from the PCA and PMF models were comparable, the PMF method is recommended for source apportionment of PAHs in real traffic conditions. In addition, the combination of multivariate statistical method and bivariate correlation analysis is a useful tool to comprehensively assess sources of PAHs.

Keywords: Atmospheric pollution; Yan'an East Road tunnel; PM${ }_{10}$; PAHs; PMF; PCA; 


\section{Introduction}

Globally urban ambient air pollution became a severe environmental problem, which obviously impaired human health (Gehring et al., 2013). Recently smog hanging over cities appears frequently in the cities of developing China, and it is the most familiar and obvious reflection of air pollution. Many visible and invisible emissions from human activities contribute to air pollution in urban atmosphere. One of the main sources is road traffic pollution (Yin et al., 2010). For example, vehicular emissions accounted for $40 \%$ of gaseous pollutants and $25 \%$ of total $\mathrm{PM}_{10}$ within the urban area of Guangzhou of China (Zhang et al., 2013). Vehicular exhaust ranked the third (at 21\%) most important source to carbonaceous particles in Shanghai (Cao et al., 2013). Along with the urbanization of China, traffic-related pollution is likely to become the largest contributor to urban air pollution (Shen et al., 2011).

Polycyclic aromatic hydrocarbons (PAHs) are typical persistent organic pollutants stemming from incomplete combustion of organic materials, e.g., gasoline combustion (Zhang et al., 2008). PAHs were selected as chemical tracers of traffic exhaust to apportion air pollution in urban atmosphere in previous studies (Jamhari et al., 2014; Khairy and Lohmann, 2013; Larsen and Baker, 2003; Yin et al., 2010). However, most of source apportionment in previous works focused on urban-scale particles (Jamhari et al., 2014; Khairy and Lohmann, 2013; Yin et al., 2010), few studies were implemented in specific traffic environment, such as particles at the side of roads (Wu et al., 2014) and in traffic tunnels (Lawrence et al., 2013). Traffic-related pollution of PAHs is a mixed emission, including gasoline and diesel exhaust, fuel evaporation, spillage of fuel and lube oil, wear and tear of brakes, tires and road surface materials, re-suspension of road dusts, partitioning, condensation, among others (Boonyatumanond et al., 2007; Harrison et al., 2003; Lawrence et al., 2013; Riddle et al., 2008; Wu et al., 2014). Understanding specific sources and their contributions to traffic-related pollution for the purpose of controlling and reducing traffic-related emission in urban atmosphere is still novel and important for improving environmental health. To our knowledge, few studies reported on source apportionment of gaseous and particulate PAHs in a traffic environment. Source apportionment was reported for a roadside environment using total concentration (gaseous plus particulate) of PAHs as variables of principal component analysis (Harrison et al., 2003). 
Previous work ranked concentrations of sedimentary PAHs in Shanghai as low to moderate on a global scale (Liu et al., 2008). PAH concentrations in rainwater (in Shanghai) were also at the high end of worldwide figures (Yan et al., 2012). Traffic-related pollution in Shanghai was considered as one of main PAH sources in air (Wang et al., 2010), sediment (Liu et al., 2009), and soil (Liu et al., 2010). Gu el al. (2010) suggested that diurnal variation of $\mathrm{PM}_{2.5}$ PAHs was related to the contribution of vehicle emission in urban areas. Therefore, it is vital to comprehensively understand PAH sources from traffic emission for reducing PAH contamination in Shanghai.

Source apportionments based on receptor modeling in most published studies were implemented via chemical mass balance (CMB) model and factor analysis methods, e.g. principal component analysis (PCA), positive matrix factorization (PMF) and UNMIX (Taiwo et al., 2014). Application of CMB model depends extremely on local profiles of all sources, whereas multivariate statistical methods based on factor analysis do not highlight a comprehensive knowledge of source composition (Pant and Harrison, 2012). However, the assignment of factors to specific source categories is highly questionable in many cases due to disturbance from extreme data and genuine collinearity of diverse sources (Larsen and Baker, 2003; Pant and Harrison, 2012). Therefore, it is necessary to remove outliers from dataset and estimate comprehensively sources factors represented when using multivariate statistical methods to apportion sources. In this work, hierarchical cluster analysis (HCA) was applied to screen outliers from dataset, and then multivariate statistical methods of PCA and PMF were used to identify main sources of gaseous and particulate PAHs, respectively. Finally bivariate correlation analysis was used to further confirm chemical sources factors reflected via investigating correlation of factor scores from PCA or factor contributions from PMF and other parameters, such as temperature, PM content, organic carbon content.

The main objectives of this study include 1) characterizing profiles and diagnostic ratios of gaseous and particulate PAHs in a typical urban tunnel of Shanghai; 2) estimating the main PAH sources in the two phases; 3) quantifying their contributions to the gaseous and particulate PAHs and $\mathrm{PM}_{10}$ mass; and 4) comparing results of source apportionment from PCA and PMF models. The results of this work provide valuable information for development of effective control policies and measures to 
decrease traffic-related air ambient contamination in urban area.

\section{Materials and methods}

\subsection{Sampling campaigns}

During 2011-2012, extensive sampling campaigns were carried out at the entrance and exit of a typical urban traffic tunnel, the Yan'an East Road Tunnel in the city center of Shanghai. Gasoline-powered vehicles dominated and accounted for $>90 \%$ of total vehicles in this tunnel. Two samplers were set up on inspection walkways, $\sim 407 \mathrm{~m}$ and $\sim 490 \mathrm{~m}$ from the entrance and exit of the tunnel. The samplers' air inlets $\left(\mathrm{PM}_{10}\right)$ were $\sim 1.5 \mathrm{~m}$ above road surface and $\sim 1 \mathrm{~m}$ away from edge of roadway. Gaseous and particulate samples were collected with medium volume air samplers using quartz fiber filters and XAD-2 resins. Traffic emissions of PAHs are combination of pyrogenic and petrogenic PAHs. It is thus better to have short sampling times under different operating conditions of tunnel so that collinearity of cases (similar contributions from similar sources in a given sample) is minimized. Three campaigns, each lasting for 15 days or more, covered spring, autumn and winter. Sampling periods also included daily and weekly variation. A total of 96 samples were collected in this study. More details were described in the Supporting Information.

\subsection{Chemical analysis}

Gaseous and particulate PAHs were measured referring to the Method TO-13a recommended by the US EPA(1999), including naphthalene (Nap), acenaphthylene (AcNy), fluorene ( $\mathrm{Fl})$, acenaphthene (AcNe), phenanthrene $(\mathrm{PhA})$, anthracene $(\mathrm{An})$, fluoranthene (FlA), pyrene (Py), benz [a]anthracene (BaA), chrysene (Chy), benzo[b]fluoranthene $(\mathrm{BbF})$, benzo $[k]$ fluoranthene $(\mathrm{BkF})$, benzo $[a]$ pyrene $(\mathrm{BaP})$, benzo[e]pyrene (BeP), perylene (Pery), indeno[1,2,3-cd] pyrene (IP), benzo[ghi]perylene (BghiP), and dibenz $[a, h]$ anthracene (DBahA). Additionally, three alkylated PAHs were measured, including methylnaphthalene (MNaP) and methylphenanthrene (MPhA) and dimethylphenanthrene (DMPhA). Organic carbon (OC) contents were determined. Carbon dioxide $\left(\mathrm{CO}_{2}\right)$ concentrations and temperature $(\mathrm{T})$ in the tunnel were recorded online. Quality assurance and quality control $(\mathrm{QA} / \mathrm{QC})$ were periodically performed. See more details in the Supporting Information. 


\subsection{Data evaluation and modeling}

Before the statistical analysis of data, undetectable values were replaced by a random number between zero and the limit of detection (LOD). PAHs with higher molecular weight than chrysene were undetectable in most gaseous samples; these gaseous concentrations were then removed from the dataset. Moreover, to determine whether the dataset was suitable for multivariate statistical analysis, we performed the Kaiser-Meyer-Olkin (KMO) and Bartlett's test of sphericity and required KMO's value of greater than 0.7 . High values (close to 1 ) usually indicate that the multivariate factor analysis may be useful with the selected dataset. Hierarchical cluster analysis (HCA) was applied to screen abnormal samples from dataset using weighted average linkage between the groups and the Euclidean distance for the cluster intervals (Kavouras et al., 2001). After removal of the anomalies, 80 samples remained for multivariate statistical analysis, which meets the minimum number of samples required for receptor modeling, namely a minimum variable to case ratio of $1: 3$ (Thurston and Spengler, 1985).

Multivariate statistical methods based factor analysis, PCA and PMF, are useful tools to apportion sources (Larsen and Baker, 2003). In PCA, all factors with eigenvalues over 1 were extracted and rotated using the Varimax method. Factor loadings and scores of PCA were used to identify main sources and quantify their contributions, respectively (Liu et al., 2009). In PMF analysis, the uncertainty file required included the calculated LODs and recovery standard deviation of the surrogate standards (Larsen and Baker, 2003) and the number of sources was set as the same as the PCA model. The converged solution with the lowest $Q$ (robust) value was selected for the further investigation. More detail can be referred elsewhere (Norris et al., 2014). Bivariate Pearson correlation analysis was applied for the purpose of exploring potential relationship within sources, temperature, $\mathrm{PM}_{10}, \mathrm{OC}$ and $\mathrm{CO}_{2}$. Multiple linear regression analysis (MLRA) was conducted using PCA factor scores or PMF factor contributions and the standardized normal deviation of total PAHs concentrations in the gas or particle phase and $\mathrm{PM}_{10}$ mass (scaled to mean and standard deviation) as independent and dependent variables, respectively. The regression was performed using a forward stepwise method. The standardized regression coefficients were used to calculate the relative contributions of major sources (Larsen and Baker, 2003; Liu et al., 2009). PCA, MLRA, HCA and bivariate correlation analysis were performed using 
SPSS statistical software packages (SPSS 13.0 for windows). The US EPA version of PMF (PMF v5.0) was used in this work.

\section{Results and discuss.}

\subsection{Profiles of gaseous and particulate PAHs}

Profiles of average concentrations of gaseous and particulate PAHs at the entrance and exit sampling sites are illustrated in Figure 1. Although PAH concentrations at the exit of the tunnel are significantly $(p<0.01)$ higher than those at the entrance, PAH profiles are similar. In this study, 2-3 rings PAHs are abundant and dominated by parent and alkylated naphthalene in the gas phase, while they are also abundant in the particle phase. In other tunnel studies, the most abundant particle-phase PAHs were 4 rings PAHs, i.e., fluoranthene and pyrene (Ancelet et al., 2011; El Haddad et al., 2009; Ho et al., 2009), or 5-6 rings PAHs, i.e., benzo[ghi]perylene and benzo[k]fluoranthene (Chen et al., 2013). Many studies suggested diesel-vehicular or heavy-duty vehicle emission were enriched in the low molecular weight PAH ( $\leq 4$ rings), whereas, the high molecular weight PAH were more abundant in gasoline engine or light-duty vehicle emission (Ancelet et al., 2011; El Haddad et al., 2009; Kam et al., 2012). In the tunnel of this study, heavy duty vehicles were restricted to pass except public transport buses and gasoline-powered medium and light duty vehicles accounted for $91-98 \%$ by manual counts based on tunnel traffic videos. The profiles of individual PAHs mainly from gasoline engine emission in this study are different from previous reports (Lima et al., 2005). Therefore, it is vital to comprehensively understand characters and sources of PAHs in the real traffic environment.

\subsection{Diagnostic ratios of gaseous and particulate PAHs}

Isomer pairs are diluted, distributed and partitioned to a similar extent to environmental receptors as they have almost identical physico-chemical properties. Diagnostic ratios (DRs), including isomer ratios, indicate intra-source variability and inter-source similarity, and provide an insight into source apportionment studies (Tobiszewski and Namiesnik, 2012). DRs of gaseous and particulate PAHs at the entrance and exit of the tunnel are statistically described in Table 1. As shown in Table 1, the DRs are comparable between the entrance and exit of the tunnel, and they reflect characteristics of gasoline-powered vehicular emission under real traffic 
conditions. It is worth noting that differences of alkylated and parent PAH DRs (i.e., $\mathrm{C}_{1} /\left(\mathrm{C}_{0}+\mathrm{C}_{1}\right) \mathrm{NaP}$ and $\left.\left(\mathrm{C}_{1}+\mathrm{C}_{2}\right) /\left(\mathrm{C}_{0}+\mathrm{C}_{1}+\mathrm{C}_{2}\right) \mathrm{PhA}\right)$ between the entrance and exit are statistically significant by the repeated measures one-way ANOVA test $(p<0.01)$. Incremented DRs are higher than the Entrance DRs and Exit DRs for particulate PAHs, indicating more alkylated PAHs were released to the particle phase in the semi-closed environment. As for gaseous PAHs, incremented DR of $\left(\mathrm{C}_{1}+\mathrm{C}_{2}\right) /\left(\mathrm{C}_{0}+\mathrm{C}_{1}+\mathrm{C}_{2}\right) \mathrm{PhA}$, as well as that in the particle phase, were also higher, whereas the incremented DR of $\mathrm{C}_{1} /\left(\mathrm{C}_{0}+\mathrm{C}_{1}\right) \mathrm{NaP}$ was lower than the corresponding DRs. It implies that, more naphthalene was released to the gas phase, or less gaseous alkylated naphthalene was emitted in the tunnel. Therefore, the difference of sources and their contributions should be further investigated by other methods in the following discussion.

\subsection{Source apportionment using multivariate statistical methods}

Outliers can severely distort representativeness of multivariate statistical analysis result. In order to improve suitability of PAHs dataset for PCA and PMF and meet requirement on KMO's value (>0.7), samples with outliers were screened by hierarchical cluster analysis (HCA). HCA can cluster outliers (cases) as single member or small cluster. After removal of the outliers, the KMO's values increased to 0.74 and 0.85 for the gaseous and particulate PAH datasets, respectively.

\subsubsection{Application of principal component analysis (PCA)}

The aim of PCA is to explain the maximum variability of original dataset with a minimum number of factors. The factors reflect specific chemical sources of target pollutants. As far as gaseous PAHs are concerned, 13 chemicals are included in the PCA model, from naphthalene (2 rings) to chrysene (4 rings). In Table 2, three factors extracted account for $83 \%$ of variability in the dataset. Factor PCA_G_1, contributing $37 \%$ of total variance, is dominated by $\mathrm{AcNy}, \mathrm{Fl}, \mathrm{PhA}, \mathrm{An}$ and FlA. High loadings of MNaP, MPhA and DMPhA and medium loadings of NaP and FlA and Py are observed in Factor PCA_G_2 which explains 29\% of the variance. Factor PCA_G_3 (17\% of the variance) is highly weighted by $\mathrm{BaA}$ and Chy. As for particulate PAHs, three principal components contain 21 chemicals, explaining $83 \%$ of total variance in Table 2. Factor PCA_P_1 (33\% of total variance) is dominated by BaA, Chy, BbF, BkF, BeP, BaP, Pery, IP and DBahA. High loadings of MNaP, AcNy, AcNe, Fl and $\mathrm{PhA}$ and medium loadings of NaP, MPhA and DMPhA are observed in Factor PCA_P_2, accounting for $28 \%$ of the 
variance. Factor PCA_P_3 (22\% of the variance) is highly weighted by An, FlA and Py, and moderately by MPhA, DMPhA, BaA and Chy.

Anthropogenic PAHs in the atmospheric environment commonly originate from petrogenic and pyrogenic sources. The former are generated from combustion procedure of organic matters under oxygen-deficient conditions (Ravindra et al., 2008), including wood, fossil fuel etc., while petroleum products, e.g., gasoline and diesel, contain petrogenic PAHs and are emitted into air by evaporation. Incomplete combustion of gasoline and diesel emits exhaust mixing with petrogenic and pyrogenic PAHs (Wallington et al., 2006). Alkylated PAHs were considered as indicators of petrogenic sources of PAHs due to the fact they are abundant in fuel oils (Dobbins et al., 2006) and eliminated in combustion process (Rhead and Hardy, 2003). Hence, Factor PCA_G_2 and PCA_P_2 are assigned to petrogenic source, e.g., evaporative emission of fuel, unburned fuel or lube oil.

Low molecular weight PAHs are emitted during low temperature combustion processes, whereas high temperature processes form higher molecular weight PAHs (Tobiszewski and Namiesnik, 2012). Increased driving speed usually leads to higher temperature of the exhaust gas (Giechaskiel et al., 2005; Kittelson et al., 2004), and vice-versa lower combustion temperature of fuel results from idling conditions (Ji and Wang, 2010). Therefore, Factor PCA_G_1, PCA_G_3, PCA_P_1 and PCA_P_3 are assigned to pyrogenic sources with different combustion temperatures. The combustion temperature of Factor PCA_G_3 was probably higher than that of Factor PCA_G_1. Similarly, the temperature of Factor PCA_P_1 was higher than that of Factor PCA_P_3. Furthermore, low loadings of alkylated PAHs in Factor PCA_G_1, PCA_G_3 and PCA_P_1 also indicate that they mainly originated not from petrogenic but from pyrogenic process. Different from them, however, medium loadings of MPhA (0.58) and DMPhA (0.69) in Factor PCA_P_3 imply that the source also contained petrogenic contribution to a large extent. Therefore, Factor PCA_P_3 is considered as a mixing source containing pyrogenic and petrogenic PAHs.

In addition, medium positive loadings of naphthalene $(0.58$ and 0.50$)$ are found in Factor PCA_G_2 and PCA_G_3, implying that chemical sources represented by the two emitted simultaneously gaseous naphthalene. This result is consistent with what was observed in diagnostic ratios of $\mathrm{C}_{1} /\left(\mathrm{C}_{0}+\mathrm{C}_{1}\right)$ Nap, further indicating more emission of gaseous naphthalene in the tunnel and its formation possibly from pyrogenic 
procedure (Factor PCA_G_3).

\subsubsection{Application of positive matrix factorization (PMF)}

PMF is a powerful multivariate technique that constraints the solution to be non-negative and takes into account the uncertainty of the observed data(Paatero and Tapper, 1994), and was strongly recommended for use in comparison to PCA (Pant and Harrison, 2012). The factor profiles of gaseous and particulate PAHs from the PMF model are shown in Table 3. The profiles in Table 3 are completely comparable and parallel with the factor loadings from PCA in Table 2 . The only differences to point out are naphthalene (NaP), acenaphthylene (AcNy) and Benzo[ghi]perylene (BghiP). The loadings of Nap are almost zero in the factors of PCA_G_1 and PCA_P_3 in Table 2, while all factors from PMF in Table 3 contain NaP more or less. Naphthalene was detected commonly in most of PAH sources. Most of AcNy and BghiP are attributed to Factor PMF_P_1 (pyrogenic source) in the PMF model, whereas in the PCA model most of AcNy belong to Factor PCA_P_2 (petrogenic source) and BghiP is almost equally separated into Factor PCA_P_1 (pyrogenic source) and PCA_P_3 (mix source). AcNy and BghiP were identified as indicators of vehicle exhaust (Larsen and Baker, 2003; Simcik et al., 1999). Hence, the result from the PMF model is more reasonable than that from the PCA model. The subtle difference in sources profiles between PCA and PMF is analyzed further in the following source estimates.

\subsubsection{Source estimates by bivariate correlation analysis.}

Bivariate correlation analysis is a useful tool to determine the empirical relationship for the purpose of testing hypotheses of association and causality. In the study, bivariate analysis is performed to explore the correlation among each factor scores of PCA, factor contributions of PMF, temperature, $\mathrm{CO}_{2}, \mathrm{PM}_{10}, \mathrm{OC}$, total concentration of particulate PAHs (PM TPAHs) and gaseous PAHs (Gas TPAHs). The Pearson's correlation coefficients are listed in Table S1. The empirical relationships are used to further estimate chemical sources represented by these factors.

Strongly significant positive correlations (marked double asterisks in Table S1) were observed amongst each other between tunnel temperature, $\mathrm{CO}_{2}, \mathrm{PM}_{10}, \mathrm{OC}$, and gaseous total PAHs (Gas TPAHs). This indicated that gasoline combustion emitted carbon dioxides, suspended particles, hydrocarbons and gaseous PAHs, and 
meanwhile released a large amount of heat increasing the temperature. Fuel evaporation is an important emission path of petrogenic PAHs and the emissions are higher at higher ambient temperature (Khairy and Lohmann, 2013; Pang et al., 2014). PCA_Gas_FS_2 was significantly positively correlated with tunnel temperatures and Factor PCA_G_2 was the one and only petrogenic source of gaseous PAHs in the PCA model. Hence, the factor is considered as evaporative emission of fuel. Compared with PCA_Gas_FS_2, no significance of correlation between the temperatures and PCA_PM_FS_2 (Factor PCA_P_2 is main petrogenic source of particulate PAHs) implies the different petrogenic sources between the gas and particle phases. A possible reason is that droplets of unburned fuel or lube oil in internal combustion engine were directly emitted to the particle phase.

$$
\text { PCA_PM_FS_3 was strongly significantly correlated with Gas TPAHs (0.36) and }
$$
Factor PCA_P_3 has been assigned to mixing source contained petrogenic and pyrogenic PAHs in the PCA model. In the vehicular tailpipe where temperatures were high, most of the volatile materials were in the gas phase. In diluting and cooling processes, the relative amounts of materials, including gaseous PAHs, nucleate to form new particles, condensed and absorbed onto existing particles (Kittelson, 1998). The transformation from gas to particle phase was widely observed in urban atmosphere as accumulation mode of particulate PAHs (Zhang et al., 2012). Strongly significant positive correlation between the factor score and $\mathrm{OC}(0.67)$ and $\mathrm{PM}_{10}(0.30)$ were also observed in Table S1. Therefore, Factor PCA_P_3 probably reflects the gas-to-particle condensation of PAHs.

Bivariate correlation results based on the PMF factor contributions were comparable to a large extent with those based on the PCA factor scores. Factor contributions in the PMF model were significantly positively correlated with factor scores in the PCA model at the 0.01 level. The strongly significant correlations mentioned above in the PCA model were also observed in the PMF model, indicating the sources identified based on the two models are, by and large, consistent. However, subtle differences between PCA and PMF are clearly shown in Table S1. The factor scores from the PCA model are orthogonal to each other (Pearson correlation coefficient $=0$ ), whereas Table S1 shows strongly significant negative correlation $(-0.29)$ between PMF_Gas_FC_1 and PMF_Gas_FC_3 and strongly significant positive correlation (0.64) between PMF_PM_FC_1 and PMF_PM_FC_2. In the PCA model, the 
orthogonal factor scores result mainly from the Varimax rotation of extracted factors, probably leading to conceal the co-variation of sources in real cases. The negative correlation of factor contributions from the PMF model reflects the inverse relationship between high-speed and low-speed traffic conditions of the tunnel, due to high-temperature combustion of fuel (PMF_G_3) at high-speed driving condition while low-temperature combustion (PMF_G_1) at low-speed driving condition (i.e., idling)(Giechaskiel et al., 2005; Kittelson et al., 2004). Likewise, the positive correlation demonstrates the co-emission of high-temperature combustion exhaust (PMF_P_1) and unburned fuel particles (PMF_P_2) in the particle phase.

The strongly significant negative correlation between emissions from low-temperature combustion (G_1) and unburned fuel particles (P_2) is found in the PCA model (-0.32), but not in the PMF model (-0.16), possibly suggesting that the association is questionable in the PCA model. In addition, strongly significant positive correlations between evaporative emission of fuel (G_2) and $\mathrm{PM}_{10}(0.50$ and 0.46$)$ and OC $(0.46$ and 0.43$)$ were all observed in the two models, but it was difficult to reasonably explain the associations based on our present understanding. Other differences and similarities of significance are also observed in the two models. More information should be added in the future investigation.

In summary, both of the multivariate statistical methods can identify the main sources of the gaseous and particulate PAHs, but the PMF results are easier to interpret and explain than those from the PCA model in this study.

\subsubsection{Source contributions to PAHs using multiple linear regression analysis}

After estimating the main sources of gaseous and particulate PAHs in the traffic tunnel, source contributions were quantified by multiple linear regression analysis (MLRA) with PCA factor scores or normalized PMF factor contributions and normalized total PAH concentrations as independent and dependent variables, respectively. The MLRA was widely applied to apportion sources of PAHs in sediments (Liu et al., 2009), urban atmosphere (Larsen and Baker, 2003) and tunnel air (Lawrence et al., 2013).

Table 4 presents the standardized regression coefficients (B) and calculated source contributions of gaseous and particulate PAHs. Determination coefficients (R squire) of 74-98\% indicated a good fit and successful application of MLRA. As for gaseous 
PAHs, the overall source contributions compared well between the two models. The first contributor was evaporation emission of fuel, accounting for 50-51\% of the mass. The following two were pyrogenic sources, accounting for 30.4-35.8\% (Factor G_3) and 13.4-19.6\% (Factor G_1), respectively. The former represented higher-temperature combustion of fuel, while the latter reflected lower-temperature combustion of fuel. As far as particulate PAHs are concerned, unburned fuel particle was the largest contributor of particulate PAHs and accounted for 56.4-78.3\% of the mass. The remaining were high-temperature combustion of fuel (9.5-26.1\%) and gas-to-particle condensation (12.2-17.5\%). In the PCA model, the contributions of petrogenic sources were $50-56 \%$ of total PAHs, in both the gas and particle phases. By contrast, the contribution of petrogenic source was obviously higher in the particle phase (78.3\%) than (56.4\%) in the gas phase in the PMF model, which was generally consistent with the results from diagnostic ratios. The source contributions based on the PMF model seemed to be more credible than the PCA results in this case.

As a consequence, the petrogenic sources, e.g., evaporative emission and unburned fuel particles, were the biggest contributors of total PAHs in the gas and particle phases. We acknowledge this study cannot reflect on total PAHs emission from local traffic. As a typical urban traffic channel, results from this tunnel can, to a large extent, be reasonably extended to the local traffic environment. Controlling emission from petrogenic sources is the most principal task for the purpose of decreasing local urban PAH contamination from traffic emission. Improving fuel efficiency will greatly reduce contribution of traffic emission to atmospheric PAHs. In addition, the contribution of secondary organic aerosol (e.g., gas-to-particle condensation) should not be ignored.

\subsubsection{Source contributions to $\mathrm{PM}_{10}$}

The MLRA also tentatively explored to apportion sources of $\mathrm{PM}_{10}$ using PCA factor scores or normalized PMF factor contributions and normalized $\mathrm{PM}_{10}$ contents as independent and dependent, respectively. Regression results are presented in Table 5. Stepwise algorithm chooses factor scores of $G_{-} 2, P_{-} 1$ and $P_{-} 3$ as predictors in the two models. The standardized coefficients (B) indicate the relative importance of the significant predictors. Evaporative emission of fuel (Factor G_2) contributes 20\% of $\mathrm{PM}_{10}$ mass. Their direct causality is hard to be explained; the result originates probably from the strongly positive significant correlation between $\mathrm{PM}_{10}$ and factor 
score of G_2 in the two models, as shown in Table4. However, a potential indirect causality or an unknown transformation of particulate matter should not be safely ignored.

$$
\text { High-temperature combustion of fuel (Factor P_1) emits 15-18\%, and the }
$$
gas-to-particle condensation (Factor $\mathrm{P}_{-} 3$ ) forms 7-8\% of the $\mathrm{PM}_{10}$. More than half of variation (55-57\%) in $\mathrm{PM}_{10}$ mass is yet unexplained based on the two models, indicating that the selected PAHs are of the limited source tracers of $\mathrm{PM}_{10}$ in the tunnel. Since particulate matters consist of inorganic (trace metals, cations and anions) and organic species, adding metal data to the organic component dataset probably decrease the unexplained contribution to $\mathrm{PM}_{10}$ mass (Harrison et al., 2003; Lawrence et al., 2013). As a result, the dataset only including organic component data is not recommended to apportion source of $\mathrm{PM}_{10}$ mass.

\section{Conclusions}

In the urban tunnel of Shanghai, 2-3 rings PAHs were abundant in the gas and particle phases. The main sources of gaseous PAHs included evaporative emission of fuel, high-temperature and low-temperature combustion of fuel. Their contributions were $50-51 \%, 30-36 \%$ and $13-20 \%$, respectively. Unburned fuel particle, high-temperature combustion of fuel and gas-to-particle condensation were major contributors of particulate PAHs in the tunnel, accounting for 56.4-78.3\%, 9.5-26.1\% and $12.2-17.5 \%$, respectively. Due to the results reflected to a large extent PAH emission in urban traffic of Shanghai, it seems to be logical to deduce that improving fuel efficiency of local vehicles will greatly reduce contribution of traffic emission to atmospheric PAHs in urban area. Contributions of high-temperature combustion of fuel and gas-to-particle condensation accounted for $15-18 \%$ and $7-8 \%$ of the $\mathrm{PM}_{10}$ mass, respectively. But yet $55-57 \%$ of the $\mathrm{PM}_{10}$ was unexplained in the present condition. The dataset only containing organic component dataset was not recommended to apportion source of $\mathrm{PM}_{10}$ mass. Although source profiles were extremely parallel based on the PCA and PMF models, source contributions to PAHs from the PMF results were more credible than that from the PCA model. Consequently, the PMF method is strongly recommended for use. Bivariate correlation analysis can be considered as one of complementary tools of the factor analysis. 


\section{ACKNOWLEDGEMENTS}

The authors would like to thank Mr. Zhe Li, Yibin Gu, Xian Lu, Jingxiao Jin from Tongji University for their help in sample collection, Mr. Jun Zheng from the Shanghai Pujiang Bridge and Tunnel Management Ltd Co. for sampling assistance and traffic video records, and Dr. Dengpan Liu from Shanghai Pudong Engineering Construction Management Ltd for sampling coordination. This work was financially supported by the National Natural Science Foundation of China (No. 20907034), and partially supported by the Fundamental Research Funds for the Central Universities of China, the 111 Project and the China Scholarship Council.

\section{REFERENCES:}

Ancelet, T., Davy, P.K., Trompetter, W.J., Markwitz, A., Weatherburn, D.C., 2011. Carbonaceous aerosols in an urban tunnel. Atmos Environ 45, 4463-4469.

Boonyatumanond, R., Murakami, M., Wattayakorn, G., Togo, A., Takada, H., 2007. Sources of polycyclic aromatic hydrocarbons (PAHs) in street dust in a tropical Asian mega-city, Bangkok, Thailand. Sci Total Environ 384, 420-432.

Cao, J.J., Zhu, C.S., Tie, X.X., Geng, F.H., Xu, H.M., Ho, S.S.H., Wang, G.H., Han, Y.M., Ho, K.F., 2013. Characteristics and sources of carbonaceous aerosols from Shanghai, China. Atmos Chem Phys 13, 803-817.

Chen, F., Hu, W., Zhong, Q., 2013. Emissions of particle-phase polycyclic aromatic hydrocarbons (PAHs) in the Fu Gui-shan Tunnel of Nanjing, China. Atmos Res 124, 53-60.

Dobbins, R.A., Fletcher, R.A., Benner, B.A., Hoeft, S., 2006. Polycyclic aromatic hydrocarbons in flames, in diesel fuels, an in diesel emissions. Combust Flame 144, 773-781.

El Haddad, I., Marchand, N., Dron, J., Temime-Roussel, B., Quivet, E., Wortham, H., Jaffrezo, J.L., Baduel, C., Voisin, D., Besombes, J.L., Gille, G., 2009. Comprehensive primary particulate organic characterization of vehicular exhaust emissions in France. Atmos Environ 43, 6190-6198.

Gehring, U., Gruzieva, O., Agius, R.M., Beelen, R., Custovic, A., Cyrys, J., Eeftens, M., Flexeder, C., Fuertes, E., Heinrich, J., Hoffmann, B., de Jongste, J.C., Kerkhof, M., Klumper, C., Korek, M., Molter, A., Schultz, E.S., Simpson, A., Sugiri, D., Svartengren, M., von Berg, A., Wijga, A.H., Pershagen, G., Brunekreef, B., 2013. Air Pollution Exposure and Lung Function in Children: The ESCAPE Project. Environ Health Persp 121, 1357-1364.

Giechaskiel, B., Ntziachristos, L., Samaras, Z., Scheer, V., Casati, R., Vogt, R., 2005. Formation potential of vehicle exhaust nucleation mode particles on-road and in the laboratory. Atmos Environ 39, 3191-3198.

Gu, Z.P., Feng, J.L., Han, W.L., Li, L., Wu, M.H., Fu, J.M., Sheng, G.Y., 2010. Diurnal variations of polycyclic aromatic hydrocarbons associated with PM2.5 in Shanghai, China. J Environ Sci-China 22, 389-396. Harrison, R.M., Tilling, R., Romero, M.S.C., Harrad, S., Jarvis, K., 2003. A study of trace metals and polycyclic aromatic hydrocarbons in the roadside environment. Atmos Environ 37, 2391-2402. Ho, K.F., Ho, S.S.H., Lee, S.C., Cheng, Y., Chow, J.C., Watson, J.G., Louie, P.K.K., Tian, L.W., 2009. Emissions of gas- and particle-phase polycyclic aromatic hydrocarbons (PAHs) in the Shing Mun Tunnel, Hong Kong. Atmos Environ 43, 6343-6351. 
Jamhari, A.A., Sahani, M., Latif, M.T., Chan, K.M., Tan, H.S., Khan, M.F., Tahir, N.M., 2014. Concentration and source identification of polycyclic aromatic hydrocarbons (PAHs) in PM10 of urban, industrial and semi-urban areas in Malaysia. Atmos Environ 86, 16-27.

Ji, C.W., Wang, S.F., 2010. Combustion and emissions performance of a hybrid hydrogen-gasoline engine at idle and lean conditions. Int J Hydrogen Energ 35, 346-355.

Kam, W., Liacos, J.W., Schauer, J.J., Delfino, R.J., Sioutas, C., 2012. On-road emission factors of PM pollutants for light-duty vehicles (LDVs) based on urban street driving conditions. Atmos Environ 61, 378-386.

Kavouras, I.G., Koutrakis, P., Tsapakis, M., Lagoudaki, E., Stephanou, E.G., Von Baer, D., Oyola, P., 2001. Source apportionment of urban particulate aliphatic and polynuclear aromatic hydrocarbons (PAHs) using multivariate methods. Environ Sci Technol 35, 2288-2294.

Khairy, M.A., Lohmann, R., 2013. Source apportionment and risk assessment of polycyclic aromatic hydrocarbons in the atmospheric environment of Alexandria, Egypt. Chemosphere 91, 895-903. Kittelson, D.B., 1998. Engines and nanoparticles: A review. J Aerosol Sci 29, 575-588.

Kittelson, D.B., Watts, W.F., Johnson, J.P., 2004. Nanoparticle emissions on Minnesota highways. Atmos Environ 38, 9-19.

Larsen, R.K., Baker, J.E., 2003. Source apportionment of polycyclic aromatic hydrocarbons in the urban atmosphere: A comparison of three methods. Environ Sci Technol 37, 1873-1881.

Lawrence, S., Sokhi, R., Ravindra, K., Mao, H.J., Prain, H.D., Bull, I.D., 2013. Source apportionment of traffic emissions of particulate matter using tunnel measurements. Atmos Environ 77, 548-557.

Lima, A.L.C., Farrington, J.W., Reddy, C.M., 2005. Combustion-derived polycyclic aromatic hydrocarbons in the environment - A review. Environ Forensics 6, 109-131.

Liu, Y., Chen, L., Huang, Q.H., Li, W.Y., Tang, Y.J., Zhao, J.F., 2009. Source apportionment of polycyclic aromatic hydrocarbons (PAHs) in surface sediments of the Huangpu River, Shanghai, China. Sci Total Environ 407, 2931-2938.

Liu, Y., Chen, L., Zhao, J.F., Huang, Q.H., Zhu, Z.L., Gao, H.W., 2008. Distribution and sources of polycyclic aromatic hydrocarbons in surface sediments of rivers and an estuary in Shanghai, China. Environ Pollut 154, 298-305.

Liu, Y., Chen, L., Zhao, J.F., Wei, Y.P., Pan, Z.Y., Meng, X.Z., Huang, Q.H., Li, W.Y., 2010. Polycyclic aromatic hydrocarbons in the surface soil of Shanghai, China: Concentrations, distribution and sources. Org. Geochem. 41, 355-362.

Norris, G., Duvall, R., Brown, S., Bai, S., 2014. EPA Positive Matrix Factorization (PMF) 5.0 Fundamentals \& User Guide. U. S. Environmental Protection Agency, Washington, DC.

Paatero, P., Tapper, U., 1994. Positive Matrix Factorization - a Nonnegative Factor Model with Optimal Utilization of Error-Estimates of Data Values. Environmetrics 5, 111-126.

Pang, Y.B., Fuentes, M., Rieger, P., 2014. Trends in the emissions of Volatile Organic Compounds (VOCs) from light-duty gasoline vehicles tested on chassis dynamometers in Southern California. Atmos Environ 83, 127-135.

Pant, P., Harrison, R.M., 2012. Critical review of receptor modelling for particulate matter: A case study of India. Atmos Environ 49, 1-12.

Ravindra, K., Sokhi, R., Van Grieken, R., 2008. Atmospheric polycyclic aromatic hydrocarbons: Source attribution, emission factors and regulation. Atmos Environ 42, 2895-2921.

Rhead, M.M., Hardy, S.A., 2003. The sources of polycyclic aromatic compounds in diesel engine emissions. Fuel 82, 385-393. 
Riddle, S.G., Robert, M.A., Jakober, C.A., Hannigan, M.P., Kleeman, M.J., 2008. Size-resolved source apportionment of airborne particle mass in a roadside environment. Environ Sci Technol 42, 6580-6586.

Shen, H.Z., Tao, S., Wang, R., Wang, B., Shen, G.F., Li, W., Su, S.S., Huang, Y., Wang, X.L., Liu, W.X., Li, B.G., Sun, K., 2011. Global time trends in PAH emissions from motor vehicles. Atmos Environ 45, 2067-2073.

Simcik, M.F., Eisenreich, S.J., Lioy, P.J., 1999. Source apportionment and source/sink relationships of PAHs in the coastal atmosphere of Chicago and Lake Michigan. Atmos Environ 33, 5071-5079.

Taiwo, A.M., Harrison, R.M., Shi, Z., 2014. A review of receptor modelling of industrially emitted particulate matter. Atmos Environ 97, 109-120.

Thurston, G.D., Spengler, J.D., 1985. A Quantitative Assessment of Source Contributions to Inhalable Particulate Matter Pollution in Metropolitan Boston. Atmos Environ 19, 9-25.

Tobiszewski, M., Namiesnik, J., 2012. PAH diagnostic ratios for the identification of pollution emission sources. Environ Pollut 162, 110-119.

US, E.P.A., 1999. Compendium method TO-13A: determination of polycyclic aromatic hydro-carbons (PAHs) in ambient air using gas chromatography/mass spectrometry (GC-MS), compendium of methods for the determination of toxic organic compounds in ambient air, second edition, EPA/625/R-96/010b, US Environmental Protection Agency, Cincinnati, OH, http://www.epa.gov/ttn/amtic/airtox.html, p. .

Wallington, T.J., Kaiser, E.W., Farrell, J.T., 2006. Automotive fuels and internal combustion engines: a chemical perspective. Chem Soc Rev 35, 335-347.

Wang, X.Y., Li, Q.B., Luo, Y.M., Ding, Q., Xi, L.M., Ma, J.M., Li, Y., Liu, Y.P., Cheng, C.L., 2010. Characteristics and sources of atmospheric polycyclic aromatic hydrocarbons (PAHs) in Shanghai, China. Environ Monit Assess 165, 295-305.

Wu, Y., Yang, L., Zheng, X., Zhang, S.J., Song, S.J., Li, J.Q., Hao, J.M., 2014. Characterization and source apportionment of particulate PAHs in the roadside environment in Beijing. Sci Total Environ 470, 76-83.

Yan, L.L., Li, X., Chen, J.M., Wang, X.J., Du, J.F., Ma, L., 2012. Source and deposition of polycyclic aromatic hydrocarbons to Shanghai, China. J Environ Sci-China 24, 116-123.

Yin, J., Harrison, R.M., Chen, Q., Rutter, A., Schauer, J.J., 2010. Source apportionment of fine particles at urban background and rural sites in the UK atmosphere. Atmos Environ 44, 841-851.

Zhang, H.R., Eddings, E.G., Sarofim, A.F., 2008. Pollutant emissions from gasoline combustion. 1. Dependence on fuel structural functionalities. Environ Sci Technol 42, 5615-5621.

Zhang, K., Zhang, B.Z., Li, S.M., Zhang, L.M., Staebler, R., Zeng, E.Y., 2012. Diurnal and seasonal variability in size-dependent atmospheric deposition fluxes of polycyclic aromatic hydrocarbons in an urban center. Atmos Environ 57, 41-48.

Zhang, S.J., Wu, Y., Liu, H., Wu, X.M., Zhou, Y., Yao, Z.L., Fu, L.X., He, K.B., Hao, J.M., 2013. Historical evaluation of vehicle emission control in Guangzhou based on a multi-year emission inventory. Atmos Environ 76, 32-42. 
Table 1. Average, $25^{\text {th }}$ and $75^{\text {th }}$ percentiles of diagnostic ratios (DRs) of gaseous and particulate PAH at the entrance and exit of the tunnel.

\begin{tabular}{|c|c|c|c|c|c|c|}
\hline \multirow{2}{*}{ Diagnostic Ratios } & \multicolumn{3}{|c|}{ Particulate PAHs } & \multicolumn{3}{|c|}{ Gaseous PAHs } \\
\hline & Entrance DR & Exit DR & Incremented DR ${ }^{\mathrm{a}}$ & Entrance DR & Exit DR & Incremented DR \\
\hline $\mathrm{C}_{1} /\left(\mathrm{C}_{0}+\mathrm{C}_{1}\right) \mathrm{NaP}$ & $0.61(0.50-0.75)$ & $0.63(0.55-0.76)^{b}$ & $0.66(0.43-0.86)$ & $0.33(0.29-0.36)$ & $0.31(0.27-0.33)^{b}$ & $0.29(0.24-0.32)$ \\
\hline$\left(\mathrm{C}_{1}+\mathrm{C}_{2}\right) /\left(\mathrm{C}_{0}+\mathrm{C}_{1}+\mathrm{C}_{2}\right) \mathrm{PhA}$ & $0.54(0.51-0.61)$ & $0.60(0.55-0.67)^{b}$ & $0.70(0.62-0.79)$ & $0.30(0.20-0.39)$ & $0.35(0.27-0.42)^{b}$ & $0.53(0.42-0.65)$ \\
\hline $\mathrm{FlA} /(\mathrm{FlA}+\mathrm{Py})$ & $0.49(0.47-0.53)$ & $0.47(0.44-0.53)$ & $0.49(0.36-0.58)$ & $0.59(0.58-0.61)$ & $0.58(0.57-0.60)$ & $0.56(0.45-0.62)$ \\
\hline $\mathrm{BaA} /(\mathrm{BaA}+\mathrm{Chy})$ & $0.32(0.30-0.34)$ & $0.31(0.29-0.33)$ & $0.33(0.26-0.37)$ & $0.32(0.26-0.37)$ & $0.33(0.29-0.35)$ & $0.34(0.20-0.43)$ \\
\hline
\end{tabular}

a, incremented DRs are based on incremented PAHs between the exit and entrance of the tunnel;

$\mathrm{b}$, the repeated measures one-way ANOVA results showed that DRs were significantly $(p=0.01)$ higher or lower at the exit than at the entrance. 
Table 2. Factor loadings of gaseous and particulate PAHs in the PCA model.

\begin{tabular}{|c|c|c|c|c|c|c|c|}
\hline \multirow{2}{*}{ No. } & \multirow{2}{*}{ PAH } & \multicolumn{3}{|c|}{ Gaseous PAHs } & \multicolumn{3}{|c|}{ Particulate PAHs } \\
\hline & & PCA_G_1 & PCA_G_2 & PCA_G_3 & PCA_P_1 & PCA_P_2 & PCA_P_3 \\
\hline 1 & $\mathrm{NaP}$ & 0.00 & 0.58 & 0.50 & 0.16 & 0.67 & -0.06 \\
\hline 2 & $\mathrm{MNaP}$ & 0.29 & 0.74 & 0.27 & 0.39 & 0.88 & 0.02 \\
\hline 3 & AcNy & 0.86 & -0.11 & 0.20 & 0.44 & 0.72 & 0.14 \\
\hline 4 & $\mathrm{AcNe}$ & 0.67 & 0.40 & 0.29 & 0.43 & 0.84 & 0.18 \\
\hline 5 & $\mathrm{Fl}$ & 0.93 & 0.13 & 0.11 & 0.42 & 0.86 & 0.19 \\
\hline 6 & $\mathrm{PhA}$ & 0.87 & 0.40 & -0.04 & 0.31 & 0.77 & 0.45 \\
\hline 7 & An & 0.93 & 0.12 & -0.15 & 0.16 & 0.15 & 0.77 \\
\hline 8 & MPhA & 0.28 & 0.92 & 0.15 & 0.26 & 0.68 & 0.58 \\
\hline 9 & DMPhA & 0.07 & 0.93 & 0.23 & 0.21 & 0.59 & 0.69 \\
\hline 10 & FlA & 0.75 & 0.54 & -0.10 & 0.25 & 0.09 & 0.91 \\
\hline 11 & Py & 0.66 & 0.63 & -0.08 & 0.20 & -0.08 & 0.91 \\
\hline 12 & $\mathrm{BaA}$ & 0.03 & 0.12 & 0.93 & 0.72 & 0.16 & 0.53 \\
\hline 13 & Chy & 0.04 & 0.27 & 0.90 & 0.70 & 0.24 & 0.53 \\
\hline 14 & $\mathrm{BbF}$ & & & & 0.87 & 0.34 & 0.29 \\
\hline 15 & $\mathrm{BkF}$ & & & & 0.79 & 0.47 & 0.17 \\
\hline 16 & $\mathrm{BeP}$ & & & & 0.78 & 0.34 & 0.44 \\
\hline 17 & $\mathrm{BaP}$ & & & & 0.81 & 0.46 & 0.29 \\
\hline 18 & Pery & & & & 0.70 & 0.45 & 0.33 \\
\hline 19 & IP & & & & 0.82 & 0.30 & 0.26 \\
\hline 20 & DBahA & & & & 0.77 & 0.32 & -0.09 \\
\hline 21 & BghiP & & & & 0.61 & 0.37 & 0.51 \\
\hline \multicolumn{2}{|c|}{ Estimated source } & Pyrogenic & Petrogenic & Pyrogenic & Pyrogenic & Petrogenic & Mix \\
\hline \multicolumn{2}{|c|}{ Variance (\%) } & 37 & 29 & 17 & 33 & 28 & 22 \\
\hline
\end{tabular}

a Rotation method: Varimax with Kaiser normalization.

b Bold loadings $>0.70$, Italic loading $>0.50$.

c KMO's test results are 0.741 and 0.854 for gaseous and particulate PAHs. 
Table 3. Factor profiles (\% of species total) of gaseous and particulate PAHs in the PMF model.

\begin{tabular}{|c|c|c|c|c|c|c|c|}
\hline \multirow{2}{*}{ No. } & \multirow{2}{*}{ PAH } & \multicolumn{3}{|c|}{ Gaseous PAHs } & \multicolumn{3}{|c|}{ Particulate PAHs } \\
\hline & & PMF_G_1 & PMF_G_2 & PMF_G_3 & PMF_P_1 & PMF_P_2 & PMF_P_3 \\
\hline 1 & $\mathrm{NaP}$ & 17.6 & 50.1 & 32.3 & 21.4 & 44.5 & 34.0 \\
\hline 2 & $\mathrm{MNaP}$ & 28.6 & 49.7 & 21.7 & 7.5 & 92.5 & 0.0 \\
\hline 3 & AcNy & 73.1 & 2.8 & 24.1 & 53.3 & 37.8 & 9.0 \\
\hline 4 & $\mathrm{AcNe}$ & 44.9 & 29.3 & 25.8 & 8.7 & 85.7 & 5.6 \\
\hline 5 & $\mathrm{Fl}$ & 67.1 & 13.4 & 19.6 & 7.3 & 78.6 & 14.2 \\
\hline 6 & $\mathrm{PhA}$ & 58.4 & 26.4 & 15.3 & 7.8 & 51.0 & 41.2 \\
\hline 7 & An & 79.5 & 9.3 & 11.2 & 0.5 & 15.1 & 84.5 \\
\hline 8 & MPhA & 19.2 & 63.5 & 17.3 & 20.5 & 44.4 & 35.1 \\
\hline 9 & DMPhA & 2.1 & 76.7 & 21.2 & 21.3 & 34.7 & 44.0 \\
\hline 10 & FlA & 49.1 & 34.5 & 16.3 & 22.2 & 4.9 & 72.8 \\
\hline 11 & Py & 43.9 & 40.8 & 15.3 & 20.0 & 1.4 & 78.6 \\
\hline 12 & $\mathrm{BaA}$ & 1.2 & 0.0 & 98.8 & 69.8 & 3.9 & 26.3 \\
\hline 13 & Chy & 0.0 & 15.0 & 85.0 & 71.5 & 0.2 & 28.2 \\
\hline 14 & $\mathrm{BbF}$ & & & & 85.6 & 3.6 & 10.7 \\
\hline 15 & $\mathrm{BkF}$ & & & & 88.5 & 9.0 & 2.6 \\
\hline 16 & $\mathrm{BeP}$ & & & & 73.0 & 10.4 & 16.6 \\
\hline 17 & $\mathrm{BaP}$ & & & & 80.7 & 13.4 & 5.8 \\
\hline 18 & Pery & & & & 58.8 & 17.9 & 23.3 \\
\hline 19 & IP & & & & 83.8 & 10.6 & 5.6 \\
\hline 20 & DBahA & & & & 82.2 & 14.9 & 2.8 \\
\hline 21 & BghiP & & & & 79.6 & 7.1 & 13.2 \\
\hline \multicolumn{2}{|c|}{ Estimated source } & Pyrogenic & Petrogenic & Pyrogenic & Pyrogenic & Petrogenic & Mix \\
\hline
\end{tabular}

aBold percentage $>50 \%$, and Italic $>30 \%$. 
Table 4. Source apportionment of gaseous and particulate PAHs in the tunnel based on the models of PCA and PMF.

\begin{tabular}{|c|c|c|c|c|c|c|c|c|c|c|}
\hline \multirow{3}{*}{ Factor } & \multicolumn{5}{|c|}{ Gaseous PAHs } & \multicolumn{5}{|c|}{ Particulate PAHs } \\
\hline & \multirow{2}{*}{ Sources } & \multicolumn{2}{|r|}{ PCA } & \multicolumn{2}{|r|}{ PMF } & \multirow{2}{*}{ Sources } & \multicolumn{2}{|r|}{ PCA } & \multicolumn{2}{|r|}{ PMF } \\
\hline & & B & Contribution & B & Contribution & & B & Contribution & B & Contribution \\
\hline 1 & Low-temp. combus. & 0.272 & $19.6 \%$ & 0.230 & $13.4 \%$ & High-temp. combus. & 0.401 & $26.1 \%$ & 0.107 & $9.5 \%$ \\
\hline 2 & Evaporation & 0.695 & $50.0 \%$ & 0.874 & $50.8 \%$ & Unburned fuel particle & 0.866 & $56.4 \%$ & 0.878 & $78.3 \%$ \\
\hline \multirow[t]{2}{*}{3} & High-temp. combus. & 0.422 & $30.4 \%$ & 0.616 & $35.8 \%$ & Condensation & 0.269 & $17.5 \%$ & 0.137 & $12.2 \%$ \\
\hline & & \multicolumn{2}{|c|}{$\left(R^{2}=0.74\right)$} & \multicolumn{2}{|c|}{$\left(R^{2}=0.90\right)$} & & \multicolumn{2}{|c|}{$\left(R^{2}=0.98\right)$} & \multicolumn{2}{|c|}{$\left(R^{2}=0.91\right)$} \\
\hline
\end{tabular}


Table 5. Source apportionment of the $\mathrm{PM}_{10}$ mass in the tunnel based on the models of PCA and PMF.

\begin{tabular}{clcc}
\hline Factor & Sources & B & Contribution \\
\hline \multirow{3}{*}{ G_2 } & (PCA model) & & \\
P_1 & Evaporation & 0.494 & $20 \%$ \\
P_3 & High-temp. combus. & 0.385 & $15 \%$ \\
& Condensation & 0.205 & $8 \%$ \\
& Unexplained & & $57 \%$ \\
& (R $\left.\mathrm{R}^{2}=0.43\right)$ & & \\
& (PMF model) & & \\
G_2 & Evaporation & 0.523 & $20 \%$ \\
P_1 & High-temp. combus. & 0.467 & $18 \%$ \\
P_3 & Condensation & 0.180 & $7 \%$ \\
& Unexplained & & $55 \%$ \\
& (R $=0.45)$ & & \\
\hline
\end{tabular}


FIGURE CAPTIONS

FIGURE 1. Profiles of average concentrations of gaseous and particulate PAHs at the entrance and exit sampling locations of the tunnel. 